\title{
Del Yemboaty a la autonomía: El trabajo de Xavier Albó con los guaraní del Chaco boliviano
}

\author{
Nancy Postero \\ University of California, San Diego
}

\begin{abstract}
This article analyzes Xavier Albó's work with the Guarani people of the Bolivian Chaco, focusing on iconic texts during three important moments in Guarani history. I argue that, by documenting the structures of political economy and history under which the Guaraní have lived, as well as their cultural resources, Albó's work contributes to current debates in anthropology about the constructed, fluid, and dynamic nature of cultural identity and its relation to power and domination. His engaged academic work established the basis for understanding that contributed to concrete proposals for political change, which I call "world-making," based in culturally significant notions of autonomy and self-determination. Albó's work serves today as a valuable model of engaged academic research.

\section{Keywords}

Autonomy, engaged anthropology, governance, Guarani, indigenous peoples, power, self-determination, shamans
\end{abstract}




\section{Resumen}

Este artículo analiza el trabajo de Xavier Albó con los guaraní del Chaco boliviano, enfocándose en textos icónicos durante tres momentos importantes de la historia guaraní. Sostengo que al documentar las estructuras de la economía política y la historia bajo las cuales han vivido los guaraní, al igual que sus recursos culturales, el trabajo de Albó contribuye a los debates actuales en antropología sobre la naturaleza construida, fluida y dinámica de la identidad cultural y su relación con el poder y la dominación. Su trabajo académico comprometido estableción las bases para un conocimiento que contribuyó con propuestas concretas para el cambio político, a las que llamo "construcción de mundos," basadas en nociones de autonomía y auto-determinación culturalmente significativas. Hoy en día, el trabajo de Albó sirve como un valioso modelo de investigación académica comprometida.

\section{Palabras claves}

Antropología comprometida, auto-determinación, chamanes, gobernanza, Guaraní, poder, pueblos indígenas

\section{Introducción}

Es un enorme placer y un honor el poder hablar hoy sobre el trabajo de nuestro querido colega, Xavier Albó. Me ofrecí como voluntaria para hablar acerca de su trabajo en el Chaco con el pueblo guaraní, porque los estudios de Albó han sido fundamentales para mi propio trabajo con los guaraní en el Santa Cruz urbano. Cuando inicié mi investigación a inicios de los años noventa, todo el mundo me decía que DEBIA hablar con Albó. ¡Aunque debo admitir que me costó mucho poder conocerlo personalmente! De modo que primero decidí conocerlo a través de sus textos, y solamente después en persona. Luego, al preparar nuestra presentación para su homenaje en LASA Barcelona 2018, tuve el gusto de volver a estos primeros textos. Las copias que tengo están hechas jirones, devoradas por las termitas durante mi trabajo de campo en Santa Cruz, subrayadas con notas por todas partes, clara evidencia de cuanto las he citado una y otra vez en mis propios escritos.

Siempre me impresionó cómo Albó muestra una rica forma de entender las instituciones políticas y culturales guaraní, la cual tanto ha informado y he podido comprobar en mis propias investigaciones. En este sentido, durante los últimos ocho años, he seguido los esfuerzos por la autonomía guaraní en Charagua -ellos lograron la primera transformación de municipio a AIOC 
(Autonomía Indígena Originaria Campesina) en 2015. Volviendo a los primeros trabajos de Albó, me doy cuenta cuán profundamente estas investigaciones estaban empapadas de las nociones de autonomía guaraní. En un tiempo incluso anterior a la organización política de los guaraní, Albó escuchó su visión acerca de lyambae (libertad), y él ya creía que esta era posible. Él trabajó con ellos por más de cuarenta años, apoyando sus esfuerzos para hacer de la autonomía en términos guaraní algo posible.

En la antropología de hoy se viene dando una gran conversación acerca de cómo llevar a cabo una antropología descolonizada y comprometida. ¿Cómo estudiamos las vidas y luchas de los pueblos indígenas sin participar del ejercicio neocolonial de la otredad? ¿Cómo hacer que nuestro trabajo sea relevante y útil para las personas que estudiamos? $\mathrm{Mi}$ argumento en este artículo es que el trabajo de Albó con los guaraní nos entrega un modelo de esta antropología comprometida. Desarrollaré cuatro aspectos al respecto:

1. Al documentar las 'estructuras' de la economía política y la historia bajo las cuales han vivido los guaraní, al igual que sus 'recursos culturales', su trabajo contribuye a los debates actuales en antropología sobre la naturaleza construida, fluida y dinámica de la identidad cultural y su relación con el poder y la dominación.

2. Esto es particularmente importante porque, al reconocer al pueblo guaraní como agente político activo en coyunturas cambiantes, su trabajo académico comprometido navegó hábilmente por los dilemas de la antropología activista: por un lado, muchos quieren usar la antropología como una herramienta pragmática para las demandas políticas. Pero, por el otro lado, los antropólogos pueden caer en el peligro de reforzar nociones esencialistas de la cultura, las que se pueden instalar en las mismas estructuras de dominio que estos grupos enfrentan.

3. Albó evitó este dilema porque su trabajo académico comprometido estableció la base para un conocimiento que contribuyó con propuestas concretas para el cambio político, las que llamo "construcción de mundos", basadas en nociones de autonomía culturalmente significativas y autodeterminación. Esto ha permitido que su trabajo supere el multiculturalismo neoliberal del pasado.

4. De este modo, su antropología es tanto pragmática como esperanzadora, y en su camino ha ofrecido valiosos modelos para el trabajo académico comprometido y continúa haciendo intervenciones en los espacios/dilemas/aproximaciones que enfrentamos hoy en día. Como en este breve ensayo no puedo 
cubrir todo su trabajo con los guaraní, me enfocaré en tres textos icónicos durante tres momentos importantes de la historia guaraní.

\section{Inicios etnográficos}

A fines de los años setenta, un poco después de su formación, la ONG con la que Albó trabajó, el CIPCA (Centro de Investigación y Promoción del Campesinado), inició su trabajo en Santa Cruz y Cordillera, formando lo que ellos Ilamaron CDTs (Comunidades de Trabajo), proyectos agrícolas colectivos que buscaban promover la solidaridad y aumentar los ingresos de estas comunidades. El primero de ellos fue implementado en la comunidad guaraní de El Espino (cerca de Gutiérrez). En ese tiempo, los guaraníes vivían en una pobreza abrumadora, trabajando como peones en haciendas de las élites mestizas locales o como trabajadores migrantes en la zafra del azúcar. Los trabajos tempranos del CIPCA denunciaron la explotación laboral en las haciendas y los campamentos de migrantes, pero también mostraron como esta era facilitada por líderes guaraníes que operaban como enganchadores, contratando la fuerza laboral para las plantaciones de caña.

Luego del retorno a la democracia en 1982, el CIPCA inició su apoyo a líderes guaraníes que recién comenzaban a organizarse. Durante 1986 y 1987, el CIPCA trabajó con ellos para realizar un enorme diagnóstico de la zona de Cordillera. Se sostuvieron reuniones y asambleas en cada zona, documentando eventualmente la situación en 72 comunidades. Los resultados se publicaron en un documento de múltiples volúmenes, co-producido con CORDECRUZ, la institución de desarrollo departamental. Este diagnóstico apoyó a las comunidades y sus líderes en su decisión de formar una organización regional y una plataforma política que permitiera que los guaraníes enfrentaran juntos sus problemas comunes (CIPCA-CORDECRUZ 1986). El resultado fue la Asamblea del Pueblo Guaraní (APG), que se formó en 1987, y que continúa siendo una de las organizaciones indígenas más importantes del país.

Durante este trabajo, Albó llevó a cabo una investigación etnográfica a través de esta región. Su libro de 1990 La Comunidad Hoy fue un proyecto en conjunto con los historiadores Bartomeu Melià y Francisco Pifarré: la trilogía seminal Los Guarani-Chiriguano, que documenta la historia, identidad, cultura y realidades de los guaraní de Bolivia (CIPCA 1990). Albó también publicó algunos trabajos en el volumen Chiriguano editado por el antropólogo Jürgen 
Riester de la ONG APCOB, cuyo trabajo se enfoca mayormente en la región guaraní de Izozog (Riester 1994). Este fue un momento clave para el trabajo académico sobre los guaraní.

Lo que emerge del maravilloso trabajo etnográfico de Albó en este período es la manera en que cultura, economía y política están siempre entrelazadas. Presagiando el enfoque actual sobre la colonialidad y los estados colonizadores, el libro parte por reconocer que los guaraníes contemporáneos aún sufrían del trauma de la derrota de 1892 en Kuruyuki, donde el ejército boliviano masacró a miles de guerreros guaraníes, extendiendo el dominio estatal, las misiones franciscanas y la presencia de ganaderos mestizos. Albó describe los efectos materiales y económicos de esta subordinación: desposesión de sus tierras, explotación laboral, una vida móvil tras el trabajo en las tierras desde Cordillera a Santa Cruz o Argentina y una subsistencia marginalizada en las tierras remanentes.

Aunque la mayor parte del libro analiza las relaciones sociales que marcan la vida guaraní, los extensos capítulos etnográficos documentan el liderazgo y sus costumbres y el yemboaty o asamblea y su proceso de toma de decisiones. Esto puede sonar como el funcionalismo estructural ya superado, pero estos textos describen lo que Gramsci llama senso commune o sentido común de la vida social y política -herramientas culturales que los guaraníes siguen utilizando para construir su autonomía. Albó describe una tensión fundamental dentro de esta sociedad. Por una parte, los guaraníes afirman un profundo deseo de libertad, la creencia de que cada persona debiera vivir como ella desee, sin ser acosada, disfrutando de la tranquilidad y moviéndose a sus anchas. Esta noción de libertad es sentida a nivel individual, y es capturada en la idea de i jambae, que literalmente significa "sin dueño" $(1990,241)$. Dada la posición estructural de peonaje en la que la mayor parte de los guaraníes vivió después de Kuruyuki, el término fue, y sigue siendo, extremadamente significativo.

A pesar de este enfoque en la libertad individual, la comunidad también debe trabajar de manera conjunta. Albó explica que el mecanismo que hace esto posible es el yemboaty, la asamblea donde la comunidad se reúne para tomar decisiones consensuadas. El consenso es promovido por los líderes políticos, los mburuvicha, (a menudo traducido al español como "capitanes"), por una parte, y por los ipayes o chamanes, por otra. Usando extensas entrevistas e historias de vida de líderes que los guaraníes consideran particularmente buenos y particularmente malos, Albó muestra que los guaraníes esperan que sus líderes sean valientes, sepan como defender 
a su gente y reciban y entreguen consejos. Es de vital importancia que sepan recoger los consejos del colectivo expresado en yemboatys o asambleas, permitiendo que todos hablen y promoviendo el consenso. Los buenos líderes interfieren lo menos posible con la autonomía de su gente, y en su lugar trabajan para llevar a cabo los deseos del colectivo. Sin embargo, con frecuencia mantienen el poder durante décadas, y tienen el poder para usar la fuerza con el fin de llevar adelante los deseos de la asamblea.

Por su parte, el ipaye moviliza a la comunidad hacia el consenso por otros medios, diagnosticando los problemas comunitarios, y a veces usando sus poderes de adivinación para determinar quien utilizó brujería maligna para "atajar la lluvia" y producir sequías. Al nombrar a dichos actores, quienes a veces son perdonados y a veces asesinados, los ipayes actúan como importantes agentes de control social, catalizando el sentimiento de la comunidad y creando ocasionalmente una válvula de escape para tensiones crecientes. Albó documenta la forma en que esto funciona en varios casos de brujería increíblemente detallados, y muestra la delicada posición en la que se encuentran los ipayes: si ellos leen correctamente el sentimiento comunitario, las tensiones se diluyen, pero si no lo hacen, ellos mismos pueden ser acusados de ser los causantes de la sequía o brujería.

Lo que es verdaderamente especial acerca de esta hermosa etnografía es que Albó presenta lo que él llamaría instituciones o roles "tradicionales" o "consuetudinarios" como parte del rico tejido de la vida guaraní contemporánea, en constante cambio en relación a la economía política en la que los guaraníes están insertos. Ellos describen su sociedad como ñandereko, "nuestra forma de vida" o "la vida armoniosa". Tal como Melià explica, este término se refiere no solamente a la cultura y costumbres guaraní, sino también al lugar y medio que hace que esta forma sea posible: la interrelación entre lo cultural, lo económico, lo social, religioso y lo político como espacios que vinculan tierra, seres y personas (Melià, citado en Medina 2002, 100-101).

Sin embargo, Albó no trata estas tradiciones como dadas. En lugar de esto, él documenta la importancia de la llegada de las misiones evangélicas en esta zona (mayormente guaraníes retornando de Argentina), la rápida expansión del protestantismo en las comunidades guaraní, y muestra cómo surgió un culto combinando patrones guaraníes de seguir a un profeta con la nueva religión (Riester 321 y ss.). ¡En su visión, la cultura no es de ninguna manera estática! Estas son comunidades en acción, trabajando, reuniéndose en yemboaty, celebrando en aretes o fiestas. El pueblo guaraní tampoco es 
presentado como homogéneo. En lugar de esto, a través de una rica etnografía, conocemos a muchos individuos, algunos son virtuosos, otros censurados y despreciados por sus comunidades por aprovecharse de su posición. Algunos ipayes aparecen como farsantes, mientras que otros llevan a cabo su rol consuetudinario con dignidad. Estos líderes deben moverse entre el pueblo guaraní, los karais/blancos y el estado, manteniendo un complejo equilibrio político en la coyuntura que ellos habitan.

Tanto más importante, vemos las nociones de iyambae y yemboaty como ideas complejas que permiten que los miembros de las comunidades guaraní entiendan y negocien sus vidas y su posición subordinada, y formulen propuestas sobre el futuro. El libro termina con un capítulo llamado "Propuestas y Contrapropuestas" en el cual Albó describe los esfuerzos que los guaraní y sus aliados hacían para organizarse. Estos incluían las CDT que el CIPCA apoyaba; los infructuosos intentos de la Federación Nacional del Trabajo, la CSUTCB, para organizarlos como sindicatos; participando de la recién formada organización nacional indígena, CIDOB (Confederación de Pueblos Indígenas del Oriente Boliviano) y la formación de la APG. Esta es, para mí, la contribución más importante de Albó. Las lógicas culturales guaraní son entendidas como herramientas en un proceso político complejo y en movimiento. En los últimos años mi colega Eli Elinoff y yo hemos reflexionado acerca de como definir lo político. Hemos reunido varios marcos teóricos -desde Gramsci a Rancière- para definir lo político de este modo: "una práctica que construye mundos que procede a través de una constelación de crítica, disenso, diferencia y conflicto" (Postero y Elinoff 2019). Esperamos que esta definición nos ayude a entender que lo político emerge de la crítica, la diferencia y el disenso, lo que -en ciertas situacionespuede llevar al cambio, lo que llamamos "construcción de mundos." Con nosotros colabora la antropóloga Tania Li, quien examina cómo y bajo que condiciones la gente se mueve desde la crítica de su situación actual hacia una política efectiva, y cuándo y por qué esto no ocurre. Ella pregunta: ¿qué formas del sentido común dan paso a una conciencia de la desigualdad, el descontento o la crítica? ¿Cómo esta crítica es compartida o enunciada? ¿De qué modo esta crítica reúne grupos sociales? (Li 2019). Por supuesto que rastrear este proceso es mucho más sencillo en retrospectiva que durante su desarrollo en el presente.

Entrego este marco conceptual para argumentar que Albó estaba haciendo precisamente este tipo de análisis político, trazando la aparición de la crítica indígena que, finalmente, cuarenta años después, comienza 
a producir formas potencialmente significativas de construir mundos: implementando la primera Autonomía Indígena Originaria Campesina (AIOC) en Bolivia. La crítica inicial y su organización, que él documentó y apoyó a través del CIPCA, se llevó a cabo en una coyuntura particular: la era del multiculturalismo neoliberal. La APG y la CIDOB eran capaces de hacer importantes - pero limitadas- demandas al estado, las que vemos ahora en perspectiva como estableciendo el escenario para las luchas actuales. Algunos antropólogos pudieron haber leído a los guaraníes simplemente como "diferentes", tanto atrapados en el yugo de la dominación karai y continuando tradiciones exóticas, incluyendo la brujería, o usando tal diferencia como base para el reconocimiento neoliberal. En vez de esto, Albó vio las ideas guaraníes como la fundación de una crítica que construye mundos, la que puede entroncarse con lo que el investigador de la nación Yellowknives Dene, Glen Coulthard, Ilama "auto-determinación significativa" (2014).

\section{Hacia la Plurinacionalidad: la Asamblea Constituyente}

Si Albó fue un importante testigo y recopilador en la etapa donde se critica al multiculturalismo, se convirtió en un importante actor político en el escenario plurinacional. Al haber trabajado con organizaciones indígenas en todo el país, una vez electo Evo Morales, Xavier Albó trabajó incansablemente para sintetizar sus críticas y propuestas para la Asamblea Constituyente $(\mathrm{AC})$. Aquí solo quiero enfocarme en la más importante de sus publicaciones: Por una Bolivia Plurinacional e Intercultural con Autonomías, co-escrita con Franz Xavier Barrios Suvelza en 2006 durante la AC, y publicada por el PNUD en 2007. Cada delegado a la AC recibió una copia de este trabajo.

Este libro reunió toda la literatura sobre nacionalismo y sus alternativas: plurinacionalismo, plurinacionalidad y autonomía. El libro hizo una importante propuesta, una suerte de esquema de lo que un sistema plurinacional con autonomías debería contener. Junto al borrador constitucional escrito por las organizaciones indígenas reunidas en el Pacto de Unidad, este texto proveyó una importante herramienta a los "constituyentes" en su lucha por crear una Bolivia nueva y diferente. La propuesta de 26 puntos con la demanda de los pueblos indígenas de ser reconocidos como "naciones," representó un desafío significativo para la soberanía nacional. Propuso este artículo: 
Art 2: En la medida que estas diversas identidades étnicas y culturales son consideradas algo fundamental e irrenunciable de los pueblos que las viven, el estado puede y tal vez debe acordarles el rango de naciones o nacionalidades y, por tanto, definirse a sí mismo como un estado plurinacional.

Otros artículos demandan interculturalidad, pluralismo legal/jurídico, control territorial y ciudadanía igualitaria. Albó y Suvelza incluyeron detallados diagramas para mostrar cómo las jurisdicciones debieran ser compartidas para varios asuntos. Más importante aún, Albó puso sobre la mesa la cuestión de la autonomía. Inició sus definiciones volviendo a la noción guaraní de iyambae, argumentando que el estado-nación, tal como los líderes guaraníes, deberían dejar el mayor espacio de acción posible a la gente, quienes eran "libres y autónomos". En su cuidadoso mapeo de competencias, imagina el gobierno indígena autónomo en varios niveles: regional, municipal, territorial, etc.

Como sabemos bien, no todas estas propuestas (ni las del Pacto de Unidad) fueron aceptadas en la constitución final. Yo, junto a otros (Tapia 2010, Garcés 2011) hemos criticado la limitada versión de autonomía que resultó finalmente. En sus memorias, Albó describe la constitución resultante como "barroca," y argumenta que para entenderla hay que ver las distintas lógicas que están en tensión dentro de ella: nociones y tecnicismos legales junto a lógicas y demandas de los pueblos indígenas (Albó 2017, 385). Sin embargo, me siento inspirada por el esperanzador y pragmático esfuerzo de Albó al apoyar el empuje para la construcción de mundos que los pueblos indígenas expresaron en la AC.

\section{Poniendo estas propuestas en acción: Autonomía Indígena en el Chaco}

Finalmente, quisiera describir brevemente la última etapa del trabajo de Albó con los guaraní: el increíble libro de 2012 El Chaco Guaraní, Camino a la Autonomía Originaria, Charagua y Gutiérrez, acompañado de un volumen sobre los esfuerzos por la autonomía en los Andes, Tres Municipios Andinos, Camino a la Autonomía Indígena: Jesús de Machaca, Chayanta, y Tarabuco (CIPCA y Ministerio de Autonomías). En él, Albó provee un magistral resumen de la historia y organización guaraní. La contribución de este volumen es la detallada historia política de cómo los guaraníes utilizaron estratégicamente cada apertura política -desde la CDT de los 1980s a las reformas neoliberales de los 1990s hasta la constitución de 2009. 
Él detalla cómo sacaron ventajas de la reforma al INRA en 1996 y así ganar títulos territoriales sobre millones de hectáreas y también co-administrar el enorme parque nacional Kaa lya. Luego de la promulgación de la Ley de Participación Popular de 1994, los guaraníes se presentaron a elecciones de alcaldes y consejeros en sus ciudades. Albó documenta cada elección desde 1995, mostrando cómo ellos negociaban con diferentes partidos políticos para ganar limitadas cuotas de poder, así como las dramáticas divisiones y traiciones entre los grupos guaraníes. Finalmente, describe cómo los líderes en Charagua pudieron ganar el referéndum de 2012 que les permitió iniciar el proceso de autonomía. Otros, incluyendo a Jason Tockman (2014), Pere Morell Tora (2013), y yo misma (Postero 2017), lo hemos retomado desde ahí, analizando este fascinante proceso en el cual los guaraní operan en "espacios intersticiales" entre los partidos políticos, vecinos hostiles, y las presiones del estado liberal, para conformar la primera Autonomía Indígena Originaria Campesina (AIOC).

Lo que esta última etapa del trabajo académico de Albó muestra es lo arduo del trabajo político: el cuidadoso diseño estratégico, hacer alianzas y las inevitables derrotas. Tanto los guaraníes como él han pasado décadas juntos, yendo y viniendo entre la crítica y la propuesta, por un lado, y el trabajo pragmático de hacer política, haciendo de esas críticas algo tangible que efectivamente pueda cambiar al mundo, por otro. Tal como dice Albó en sus memorias, la autonomía es una utopía, una que quizá nunca se alcanzará. Sin embargo, él caracteriza a Charagua como "la lucecita" ... que tiene más chance de acercarse a la posibilidad de llegar a crear una cosa distinta..." $(2017,402)$. Que descripción más perfecta de la política.

Concluyo agradeciendo a Xavier Albó sus muchos años inspirando investigaciones, trabajo académico y activismo. Su esperanza pragmática es un modelo de antropología comprometida para todos nosotros.

\section{Bibliografía citada}

ALBÓ, Xavier. 1990. Los Guarani-Chiriguano, N³. La comunidad hoy. Cuadernos de investigación (Centro de Investigación y Promoción del Campesinado) 32. La Paz: CIPCA.

---. Y Franz Xavier Barrios Suvelza. 2007. Por una Bolivia plurinacional e intercultural con autonomías. La Paz: PNUD, IDH.

[https://cebem.org/cmsfiles/archivos/por-una-bolivia-plurinacionalintercultural-con-autonomias.pdf] página descargada el 15 de diciembre 2019. 
---. 2012a. El Chaco guaraní camino a la autonomía originaria: Charagua, Gutiérrez y proyección regional. Cuadernos de investigación (Centro de Investigación y Promoción del Campesinado) 79. La Paz: CIPCA.

---. 2012b. Tres municipios andinos camino a la autonomía indígena: Jesús de Machaca, Chayanta, y Tarabuco. Cuadernos de Investigación (Centro de Investigación y Promoción del Campesinado) 78. La Paz, Bolivia: CIPCA y Ministerio de Autonomías.

---. y Carmen Beatriz Ruiz. 2017. Un curioso incorregible. La Paz: Fundación Xavier Albó.

CIPCA-CORDECRUZ. 1986. Plan de Desarrollo Campesino de Cordillera. Diagnóstico-Estrategia. Vols. I-IV. Santa Cruz: CIPCA-CORDECRUZ.

COULTHARD, Glen. 2014. Red Skin, White Masks. Minneapolis, MN: University of Minnesota Press.

GARCÉS, Fernando. 2011. "The Domestication of Indigenous Autonomies in Bolivia: From the Pact of Unity to the New Constitution". Remapping Bolivia, Resources, Territory, and Indigeneity in a Plurinational State. Nicole Fabricant and Bret Gustafson, eds. Santa Fe, NM: School for Advanced Research Press.

LI, Tania. 2019. "Politics, Interrupted". Anthropological Theory 19(1): 29-53.

MORREL i TORRA, Pere, 2013. Autonomía guaraní Charagua Iyambae, Etnografía de una autonomía indígena en construcción. Tesis de Maestría. Universitat de Barcelona.

POSTERO, Nancy, 2017. The Indigenous State, Race, Politics, and Performance in Plurinational Bolivia. Oakland, CA: University of California Press.

---. y Eli Elinoff. 2019. "Introduction: Political Anthropology in the Age of Post-Politics. Anthropology Theory 19(1): 3-28.

RIESTER, Jürgen, ed. 1994. Chiriguano. Vol. 3. Santa Cruz: Apoyo para el Campesino-Indígena del Oriente Boliviano, APCOB.

TAPIA, Luis. 2010. "Consideraciones sobre el Estado Plurinacional". Descolonización en Bolivia, cuatro ejes para comprender el cambio. La Paz: Vicepresidencia del Estado.

TOCKMAN, Jason. 2014. Instituting Power: Power Relations, Institutional Hybridity, and Indigenous Self-Governance in Bolivia. Tesis de Doctorado. University of British Columbia.

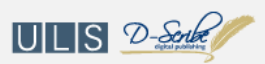

New articles in this journal are licensed under a Creative Commons Attribution 4.0 United States License.

This journal is published by the University Library System of the University of Pittsburgh as part of its D-Scribe Digital Publishing Program, and is cosponsored by the University of Pittsburgh Press. 